Solid-liquid interdiffusion (SLID) bonding in the Au-In system: experimental study and 1D modelling

This content has been downloaded from IOPscience. Please scroll down to see the full text. 2015 J. Micromech. Microeng. 25125016

(http://iopscience.iop.org/0960-1317/25/12/125016)

View the table of contents for this issue, or go to the journal homepage for more

Download details:

IP Address: 128.178.99.147

This content was downloaded on 17/02/2016 at $16: 23$

Please note that terms and conditions apply. 


\title{
Solid-liquid interdiffusion (SLID) bonding in the Au-In system: experimental study and 1D modelling
}

\author{
Léa Deillon ${ }^{1,2}$, Aïcha Hessler-Wyser ${ }^{1}$, Thierry Hessler ${ }^{3}$ and Michel Rappaz ${ }^{2}$ \\ ${ }^{1}$ Centre Interdisciplinaire de Microscopie Électronique, École Polytechnique Fédérale de Lausanne, \\ 1015 Lausanne, Switzerland \\ ${ }^{2}$ Laboratoire de Simulation des Matériaux, École Polytechnique Fédérale de Lausanne, 1015 Lausanne, \\ Switzerland \\ ${ }^{3}$ Institut d'Horlogerie et Création, Haute Ecole Arc, 2400 Le Locle, Switzerland \\ E-mail: lea.deillon@epfl.ch
}

Received 17 July 2015, revised 7 September 2015

Accepted for publication 22 September 2015

Published 3 November 2015

\begin{abstract}
$\mathrm{Au}-\mathrm{In}$ bonds with a nominal composition of about 60 at.\% In were fabricated for use in wafer-level packaging of MEMS. The microstructure of the bonds was studied by scanning electron microscopy. The bond hermeticity was then assessed using oxidation of $\mathrm{Cu}$ thin discs predeposited within the sealed packages. The three intermetallic compounds $\mathrm{AuIn}_{2}, \mathrm{AuIn}$ and $\mathrm{Au}_{7} \mathrm{In}_{3}$ were observed. Their thickness evolution during bonding and after subsequent heat treatment was successfully modelled using a finite difference model of diffusion, thermodynamic data and diffusion coefficients calibrated from isothermal diffusion couples. $17 \%$ of the packages were hermetic and, although the origin of the leaks could not be clearly identified, it appeared that hermeticity was correlated with the unevenness of the metallisation and/or wafer and the fact that the bonds shrink due to density differences as the relative fractions of the various phases gradually evolve.
\end{abstract}

Keywords: gold, indium, diffusion, SLID bonding, TLP bonding, intermetallic compounds growth

(Some figures may appear in colour only in the online journal)

\section{Introduction}

Hermeticity is an essential requirement of a micro-electromechanical systems (MEMS) package for a device to work properly. It must therefore be preserved during operations following packaging (e.g. mounting on printed circuit boards), during which the package bond should not remelt. The bonding temperature is limited, however, to avoid damaging the device being encapsulated. Solid-liquid interdiffusion (SLID) bonding [1, 2] is interesting in this context, because this process allows one to achieve bonds that are able to subsequently withstand higher temperatures than the temperature at which the bonding is done. The process consists in bringing together two metallic layers with respectively high and low melting points. By heating the system to a temperature above the lowest melting point, one or more intermetallic compounds (IMC) form by interdiffusion, their melting temperature usually being in between those of the two initial materials. The SLID and transient liquid phase (TLP) bonding processes share many similarities. The term SLID bonding is usually preferred when new phases are formed within the bond, but both terms are increasingly used interchangeably.

The optimal process time and temperature depend strongly on the growth kinetics of the IMCs that are formed. As shown by the phase diagram in figure 1 , the $\mathrm{Au}-\mathrm{In}$ system meets the specific requirements aimed at fabricating SLID bonds. Already in 1966, Bernstein [1] described the IMCs that formed in the $\mathrm{Au}-\mathrm{In}, \mathrm{Ag}-\mathrm{In}$ and $\mathrm{Cu}-\mathrm{In}$ binary systems after contacts of $10-120 \mathrm{~min}$ in the temperature range $200-450{ }^{\circ} \mathrm{C}$. Mostly qualitative results were presented and the various IMCs were 


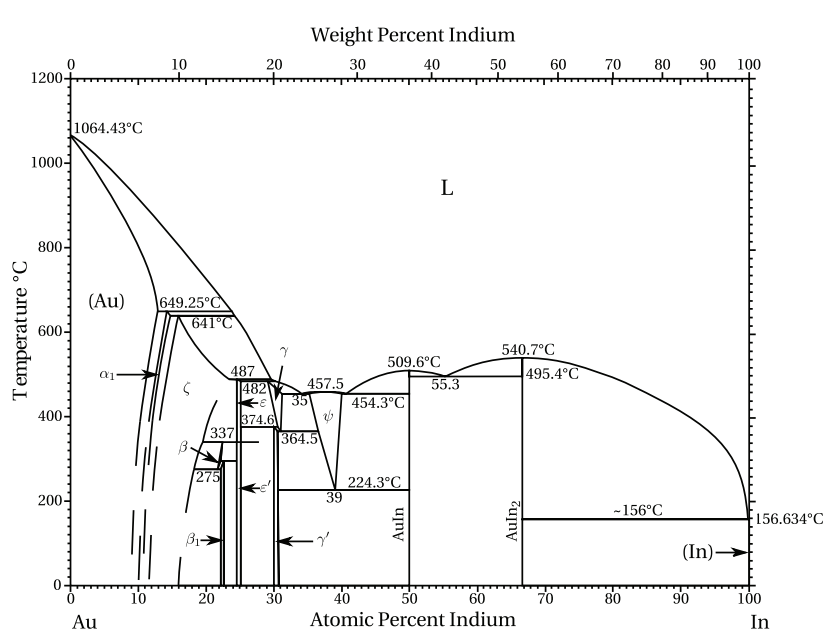

Figure 1. The Au-In binary phase diagram [3]. Reproduced with permission from Okamoto and Massalski T 1986 Binary Alloy Phase Diagrams vol. 1, copyright 1986 ASM International.

mainly identified by their specific colour using optical microscopy. Consequently, the reported results are probably only partially correct, especially since the corresponding phase diagrams were reassessed later.

More recently, $\mathrm{Au}-\mathrm{In}$ bonding tests were performed by several groups [4-10] and are not exhaustively listed here. The parameters of the bonding process were varied, in particular the bonding temperature between 180 and $300{ }^{\circ} \mathrm{C}$ and the contact time from $5 \mathrm{~s}$ up to $30 \mathrm{~min}$. There were also large differences in the nominal composition of the bonds, which ranged from 7 to 60 at.\% In. A pressure, from 0.02 to $8 \mathrm{MPa}$, was additionally applied during the bonding process in all cases. From these various studies, it was found that the microstructure of the bonds always exhibits the AuIn 2 phase [5-9]. The AuIn phase was also found in a few cases, but only as a thin layer $[6,7,9]$, while $\mathrm{Au}_{7} \operatorname{In}_{3}\left(\gamma^{\prime}\right)$ was observed when the In content was less than 50 at.\% [6, 7]. Au-richer phases might have appeared, but were never clearly identified. A few microscopic voids were observed when the bonding time was only a few seconds $[5,8,9]$, but fewer voids formed at longer interaction times $[4,6,7]$.

The work of Waelti [7] is of particular relevance as it represents the only available study concerning the hermeticity of $\mathrm{Au}-\mathrm{In}$ bonds. This author fabricated Au-rich bonds and, using integrated pressure sensors, showed that the best results were obtained after $10 \mathrm{~min}$ at $195^{\circ} \mathrm{C}$ and with an applied pressure of $8 \mathrm{MPa}$ : the bonds were hermetic and did not reflow below $473{ }^{\circ} \mathrm{C}$. However, their composition was too rich in $\mathrm{Au}$ to be economically interesting in most production processes. It should also be mentioned that the applied pressure required to obtain hermetic bonds is strongly dependent on the roughness and flatness of the contact surfaces (i.e. the uniformity of the deposit thicknesses on a whole wafer and the wafer itself).

The aim of the present paper is to describe a novel way of fabricating hermetic bonds for application in the wafer-level packaging (WLP) of MEMS. Compared to the widespread $\mathrm{Au}-\mathrm{Sn}$ eutectic bonds, which contain $80 \mathrm{wt} \% \mathrm{Au}$ and melt at $278{ }^{\circ} \mathrm{C}$, the bonds described here present not only an undeniable

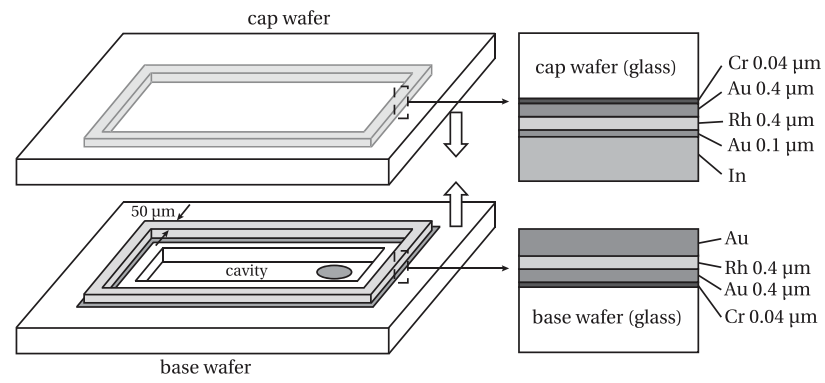

Figure 2. Schematic representation (not to scale) of a bonding frame with the small $\mathrm{Cu}$ disc used for hermeticity testing and the metallisation layers deposited on the base and cap wafers.

economic advantage but are also able to withstand much higher temperatures $\left(495{ }^{\circ} \mathrm{C}\right)$. The microstructure of $\mathrm{Au}-\mathrm{In}$ bonds is studied in detail and their hermeticity is assessed. Based on recent results of $\mathrm{Au}-\mathrm{In}$ diffusion couples $[11,12]$, the diffusion coefficients within the various phases in the bond microstructure were determined with the help of a 1D numerical model. In the present contribution, this model is first adapted to finitesize domains with typical thicknesses of a few microns, for both the liquid solder and the Au substrate. It is then applied to simulate the bonding process and optimise its parameters, in particular time and temperature. The density differences between the observed phases are moreover taken into account in order to predict the final thickness of the bond. As shown in this work, such a combined experimental-simulation study allows us to gain a better understanding of the reaction process that takes place during the $\mathrm{Au}-\mathrm{In}$ SLID bonding.

\section{Experimental}

\subsection{Bonds fabrication}

Thin layers of chromium $(40 \mathrm{~nm})$ and gold $(400 \mathrm{~nm})$ were first deposited on borosilicate glass substrates (SCHOTT $\mathrm{D} 263^{\mathrm{TM}}, 100 \times 100 \times 0.3 \mathrm{~mm}$ ) by electron beam evaporation. Photolithography techniques were then used to structure $50 \mu \mathrm{m}$-wide rectangular bonding frames of $1.2 \mathrm{~mm} \times 0.4 \mathrm{~mm}$, each wafer including a total of 4882 frames. A $0.4 \mu \mathrm{m}$-thick rhodium layer was then electroplated to act as a barrier for the bonding reaction, prior to electroplating gold and indium according to the metallisation sequences schematically represented in figure 2 . The thicknesses of the layers were measured using a Tencor Alpha-Step (Alpha-Step is a stylus-based surface profiler produced by KLA-Tencor, Milpitas CA, USA). The cap wafer was then positioned very accurately over the base wafer to match the frames made by photolithography in order to get 4882 sealed rectangular cavities after bonding.

The bonding tests were performed in a furnace equipped with a flexible membrane which can be inserted over the preassembled wafers in order to apply a pressure $\Delta p$ during the process (see figure 3). After evacuating the whole chamber, 800 mbar of Ar was introduced for the first heat-up ramp, until reaching $100{ }^{\circ} \mathrm{C}$. At this point, the atmosphere was purged (to clean outgassed impurities) prior to reintroducing $\mathrm{Ar}$ in the whole chamber (pressure $p_{2}$ ) as well as a nitrogen overpressure 


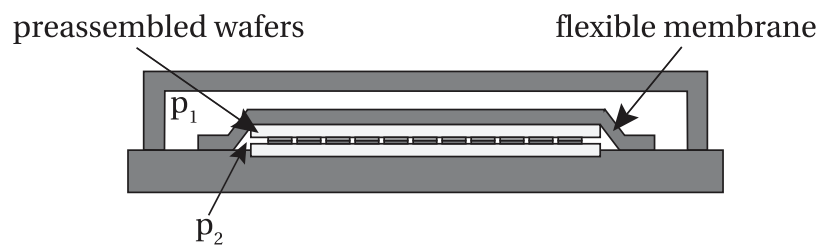

Figure 3. Schematic of the sealing furnace used for bonding tests.

$\Delta p$ in the upper part (i.e. pressure outside the membrane $\left.p_{1}=p_{2}+\Delta p\right)$. The wafers were then heated at the desired bonding temperature and cooled down after a predefined time, which depends on the specific amount of In that needs to be consumed. The cooling to room temperature took 15-20 min.

Cross-sections of the bonds were then prepared using diamond polishing discs down to $0.1 \mu \mathrm{m}$ and a final polishing with an alumina suspension $(0.05 \mu \mathrm{m})$. The microstructure of the bonds was characterised by Scanning Electron Microscopy (SEM) coupled with chemical analyses using energy dispersive $\mathrm{X}$-ray (EDX) spectroscopy.

\subsection{Hermeticity characterisation}

The hermeticity was evaluated according to the method developed by Gueissaz et al $[13,14]$. The method is based on the reaction of a thin layer of $\mathrm{Cu}$ with oxygen. For that purpose, wet etching was first used to form cavities in the glass of the base wafer (electroplated with a thicker Au layer). The outgassing step was performed and $\mathrm{Cu}$ discs with a diameter of 65 $\mu \mathrm{m}$ and a thickness of $30 \mathrm{~nm}$ were then deposited in the cavities by e-beam evaporation using a mask (see figure 2). After bonding, the wafers were placed under 14 bars $\mathrm{O}_{2}$ at $150{ }^{\circ} \mathrm{C}$ for $48 \mathrm{~h}$ in order to force the oxygen into the leaking packages under conditions that accelerate the oxidation process. The oxidation level of the $\mathrm{Cu}$ layers was evaluated by automatic measurements of their optical transmission in the near-infrared (IR) range, considering a wavelength of $875 \mathrm{~nm}$. The transmission in the glass beside each $\mathrm{Cu}$ disc was also measured and served as a reference. The transmission ratio was computed eventually and allowed us to evidence two distinct populations, corresponding respectively to hermetic and leaking packages.

This method is able to detect leak rates down to $4.3 \cdot 10^{-15}$ mbar $\cdot 1 \cdot \mathrm{s}^{-1}$ (assuming constant leak rates). The volume of the cavity is equal to $1.8 \cdot 10^{-11} \mathrm{~m}^{3}$ and therefore this leak rate corresponds to a pressure change of $2.4 \cdot 10^{-7} \mathrm{mbar} \cdot \mathrm{s}^{-1}$ (i.e. 7.6 mbar per year).

\section{Results}

\subsection{Bond microstructure}

Gold and indium thicknesses were chosen in order to have a nominal composition of the bonds near 60 at.\% In. This choice was motivated by the desire to minimise the amount of $\mathrm{Au}$ (for obvious economical reasons), while avoiding having unreacted In left in the final microstructure. Indeed, with its low melting point, indium should be fully consumed at the end
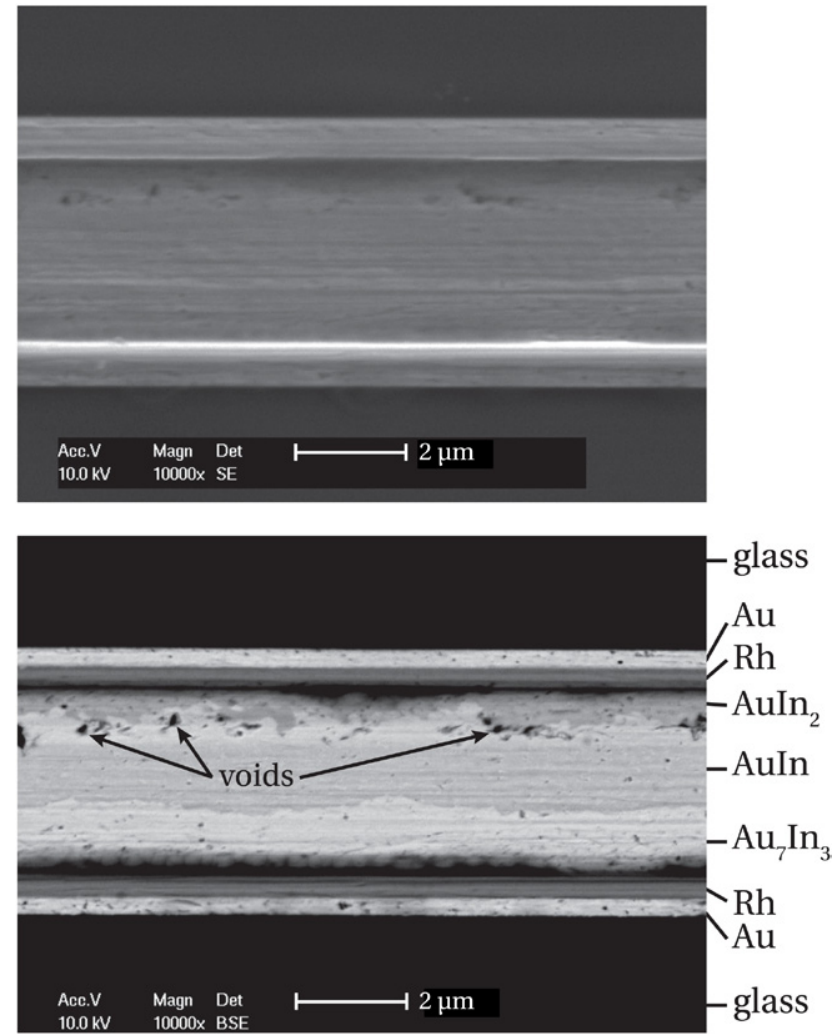

Figure 4. SEM micrographs of a bond cross-section: top SE, bottom BSE (bonding parameters: $200^{\circ} \mathrm{C}, 15 \mathrm{~min}, 1.85 \mathrm{bar}$ ).

of the bonding process to avoid partial remelting of the bonds at low temperature in subsequent mounting operations. The nominal composition was selected to have a final microstructure falling in the two-phase region $\left(\mathrm{AuIn}+\mathrm{AuIn}_{2}\right)$, which is bounded by a eutectic reaction at $495.4{ }^{\circ} \mathrm{C}$. Furthermore, a total thickness of about $5 \mu \mathrm{m}$ is needed in order to compensate the initial roughness of the glass substrates, as well as the lack of flatness induced by the thickness inhomogeneities of the electroplated layers.

The preliminary results showed that the optimal bonding temperature is $200{ }^{\circ} \mathrm{C}$. SEM micrographs of a typical bond are presented in figure 4 . The applied pressure on the top wafer (base wafer) during bonding was 1.85 bar, corresponding to a pressure of $2.5 \mathrm{MPa}$ on the bonding frames. Note that the pressure needs to be carefully chosen in order to compensate for the roughness of the substrates and deposited layers without ejecting the liquid solder. We observed that a pressure of 1.85 bar was a good compromise, for which surface tensions were sufficient to retain the solder within the bonding area. The initial thicknesses of Au and In were in this case 1.55 and $3.6 \mu \mathrm{m}$, respectively. With these initial thicknesses corresponding to a nominal composition of 59.9 at.\% In, 15 min of reaction was enough to consume all the In. We can see in the top micrograph (secondary electron (SE) contrast) that these bonding parameters allow us to obtain homogeneous bonds that are nearly void-free. Note that steps are induced by the polishing at the $\mathrm{Rh} / \mathrm{IMC}$ interfaces due to the high hardness of Rh (resulting, respectively, in the formation of a shadow and a bright line at the upper and lower interfaces in figure 4(top)). The total thickness of the bond is $4.8 \mu \mathrm{m}$ ( $\mathrm{Au}$ and $\mathrm{Rh}$ underlayers included). 
In the bottom micrograph (Back-Scattered Electrons (BSEs) contrast), the chemical contrast allows us to distinguish three IMCs that were identified as $\operatorname{AuIn}_{2}$, AuIn and $\mathrm{Au}_{7} \mathrm{In}_{3}$ by EDX analyses. The average thicknesses are $1.7 \mu \mathrm{m}$ for AuIn, $1.25 \mu \mathrm{m}$ for $\mathrm{Au}_{7} \mathrm{In}_{3}$ and $0.35 \mu \mathrm{m}$ for $\mathrm{AuIn}_{2}$. AuIn is thus found to be the major phase present in the bond, unlike in the diffusion couples experiments where this phase was always observed as a thin layer $[11,12]$, but then in a situation where both the $\mathrm{Au}$ and In base metals were semi-infinite compared to the thickness of the bond and thus available for the reaction. According to the IMCs' thickness measurements and considering solute conservation, the gold and indium thicknesses having effectively reacted are 1.6 and $1.9 \mu \mathrm{m}$, respectively. This In thickness is thus much smaller than what we measured after electroplating. This difference can be attributed to the fact that the In frame width on the cap wafer $(50 \mu \mathrm{m}$, see figure 2) is only half that of the $\mathrm{Cr} / \mathrm{Au}$ underlayers on the base wafer (100 $\mu \mathrm{m}$, shown in darker grey in the figure). During the bonding process, some In reacts with this Au underlayer, which has a small thickness but an important surface.

Few voids are found near the AuIn $2 / A u I n$ interface. These voids are of small size $(135 \mathrm{~nm}$ in average) and represent a surface fraction of only $0.25 \%$. However, some of them, especially the smallest, could have been induced by the polishing process. A second test was performed in the same conditions and showed that the results are repeatable, the aspect and composition of the bonds being similar to the bonds presented above. In addition, we observed that the application of a smaller pressure $(0.7 \mathrm{MPa})$ during bonding results in the presence of larger voids within the bond microstructure (average size of $400 \mathrm{~nm}$, surface fraction of $2.4-3.4 \%$ ).

\subsection{Hermeticity characterisation}

After sealing, the wafers were first placed under 1.5 bar Ar at $150{ }^{\circ} \mathrm{C}$ for $48 \mathrm{~h}$. This preliminary test was performed in order to ensure that outgassing would not skew the results. After this step, $97.7 \%$ of the $\mathrm{Cu}$ patterns were still assessed as good, showing that outgassing is not an issue. The hermeticity was then tested and the following IR transmission measurements showed that $16.8 \%$ of the sealings were hermetic. The results are displayed as a histogram in figure 5 , in which the number of occurrences is plotted as a function of the transmitted intensity. The left population, for which the transmission ratio is about $20 \%$, corresponds to the hermetic packages. Local SEM observations did not allow us to identify the source of the tiny leaks of the permeable bonds.

Note that after this additional heat treatment at $150{ }^{\circ} \mathrm{C}$, the bond composition has reached thermodynamic equilibrium: it is made up of only two IMCs: $\mathrm{AuIn}_{2}$ and AuIn (figure 6). The average thicknesses are then $1.6 \mu \mathrm{m}$ for $\mathrm{AuIn}_{2}$ and $1.8 \mu \mathrm{m}$ for AuIn (for the initial Au and In thicknesses of, respectively, 1.2 and $2.4 \mu \mathrm{m})$.

Some attempts were made to improve the hermeticity yield but remained unsuccessful. With a nominal composition of the bonds close to 50 at.\% In (i.e. final composition lying in the two-phase region $\mathrm{AuIn}+\mathrm{Au}_{7} \mathrm{In}_{3}$ ), only $8 \%$ of the packages were hermetically sealed. Nevertheless, after the hermeticity

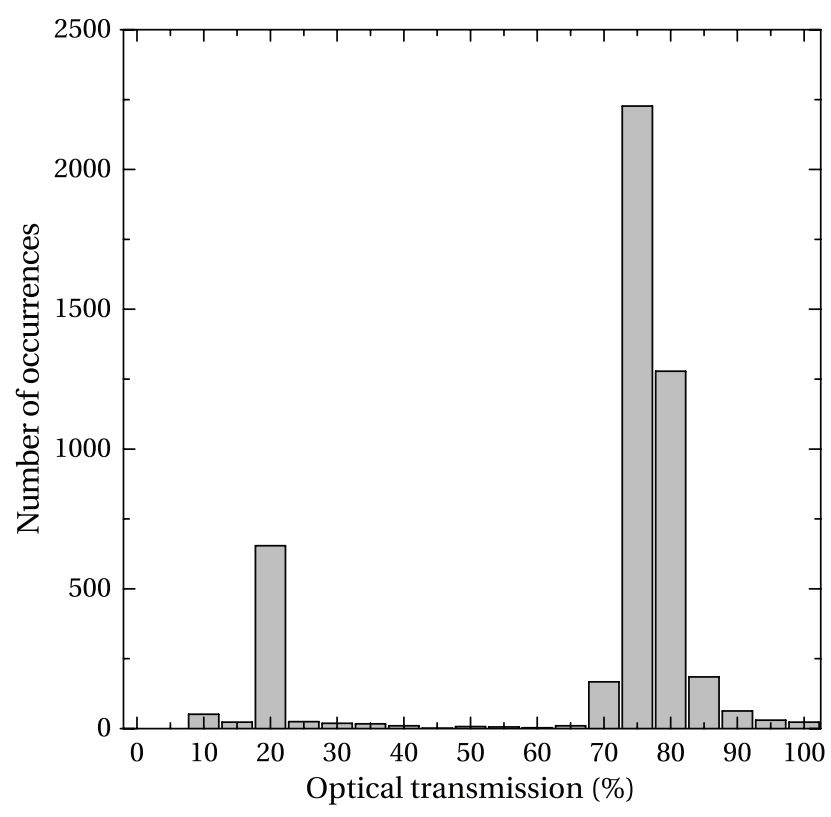

Figure 5. Distribution of the optical transmission ratio $(\lambda=875 \mathrm{~nm})$ of $\mathrm{Cu}$ discs after $48 \mathrm{~h}$ under 14 bars $\mathrm{O}_{2}$ at $150{ }^{\circ} \mathrm{C}$.

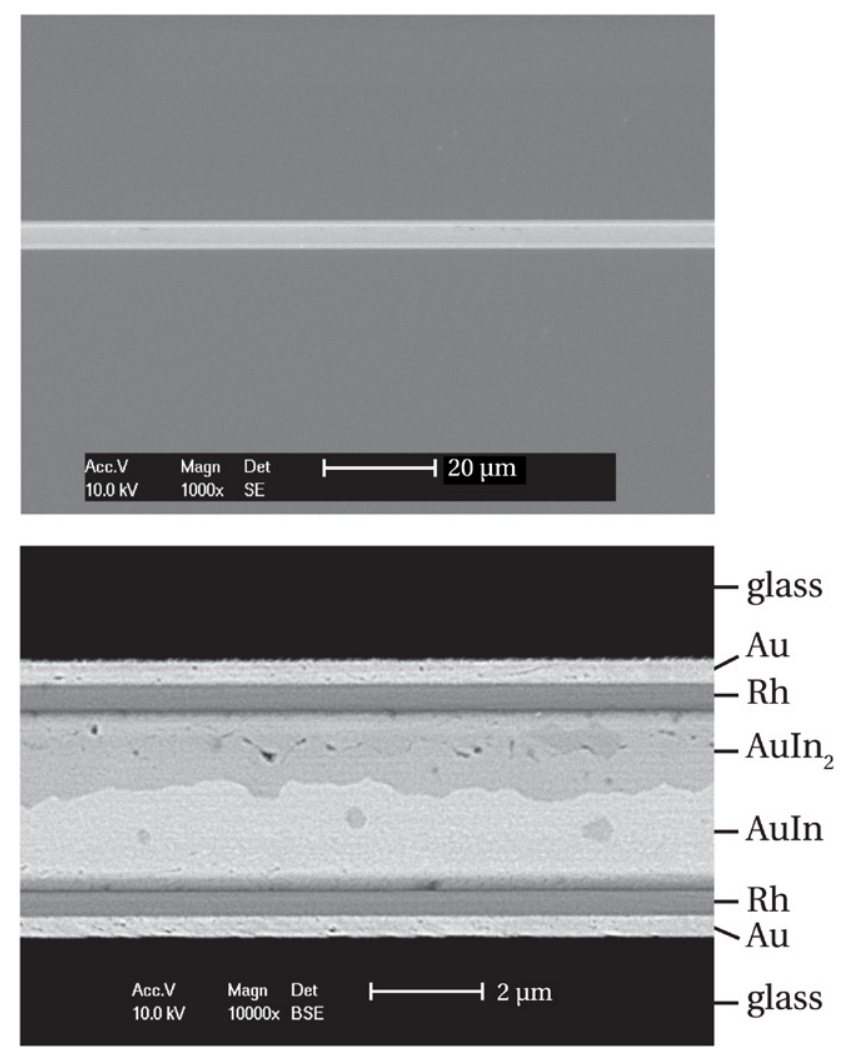

Figure 6. SEM micrographs of a bond cross-section after $96 \mathrm{~h}$ additional heat-treatment at $150{ }^{\circ} \mathrm{C}$ : top SE, bottom BSE (bonding parameters: $\left.200^{\circ} \mathrm{C}, 15 \mathrm{~min}, 1.7 \mathrm{bar}\right)$.

test, a $1 \mathrm{~h}$ reflow test at $350{ }^{\circ} \mathrm{C}$ in air was performed and approximatively $40 \%$ of the non-oxidised $\mathrm{Cu}$ patterns were then still qualified as good. This test shows that the bonds are able to withstand higher temperatures without losing hermeticity. It is much more severe than what the bonds are expected to undergo during the whole MEMS fabrication process, but 


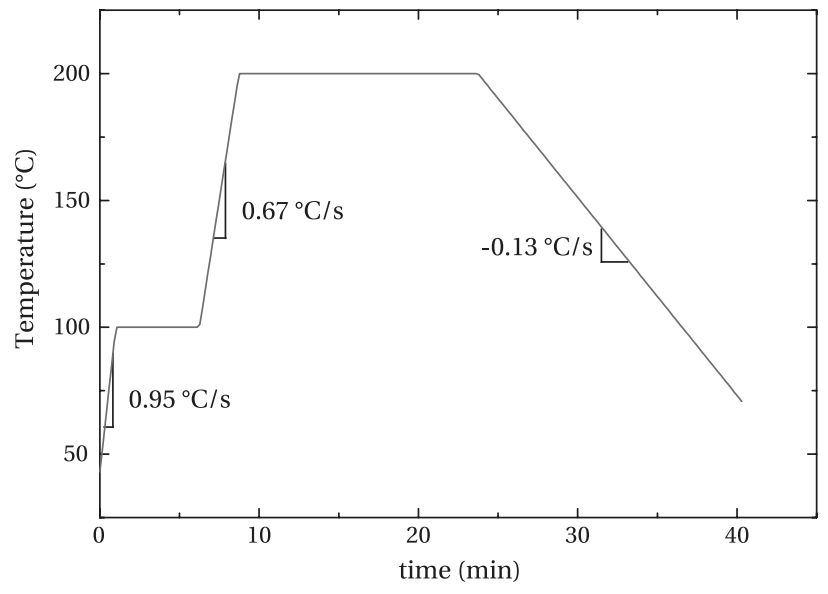

Figure 7. Temperature profile for a typical bonding process.

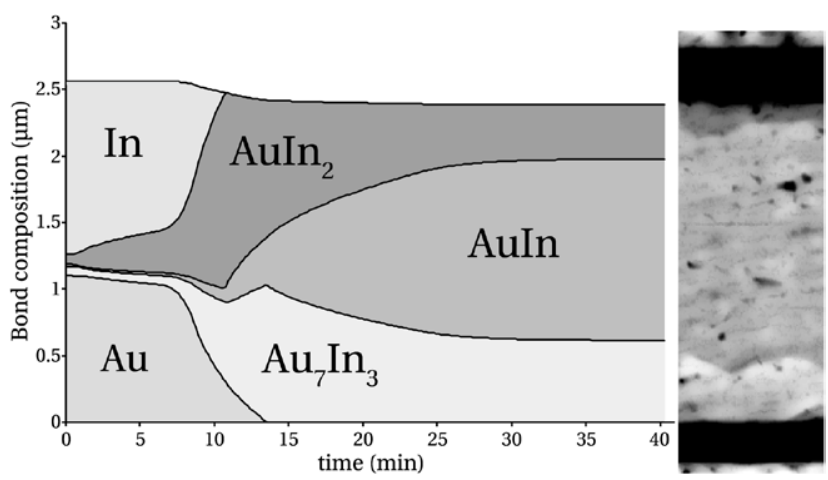

Figure 8. Left: modelling of the bonding process; to be compared with the bond shown in figure 4. Right: selected area of the same bond.

resistance to such high temperature may prove beneficial when getters are used.

\subsection{Modelling of the bonding process}

The diffusion coefficients of In through the various phases were determined by means of isothermal diffusion couples experiments in the temperature range $150-250{ }^{\circ} \mathrm{C}$, coupled with 1D finite-difference modelling of the IMCs' growth $[11,12]$. These previous results allow us to model a bonding process in which the temperature is no longer a constant and the initial In and Au layers have a finite thickness. The typical temperature profile of the bonding process is shown in figure 7 . The nucleation stage was neglected and a small initial thickness was set up to the various IMCs present in the reaction: $0.02 \mu \mathrm{m}$ for AuIn, which is only present as a thin layer in the first stages of the reaction, and $0.07 \mu \mathrm{m}$ for $\mathrm{AuIn}_{2}$ and $\mathrm{Au}_{7} \mathrm{In}_{3}$. Conversely, once the width of a domain falls below $0.1 \mathrm{~nm}$, it is assumed to have disappeared. It should be pointed out that the thin underlayers were not considered in the model. Details of the model can be found in [11, 12], but it is just recalled that: (i) the IMCs are considered to be stoichiometric and the diffusion of In is calculated in the various IMCs with the help of the chemical potentials; (ii) liquid In is considered to be saturated with $\mathrm{Au}$ (the solubility limit is small anyway)
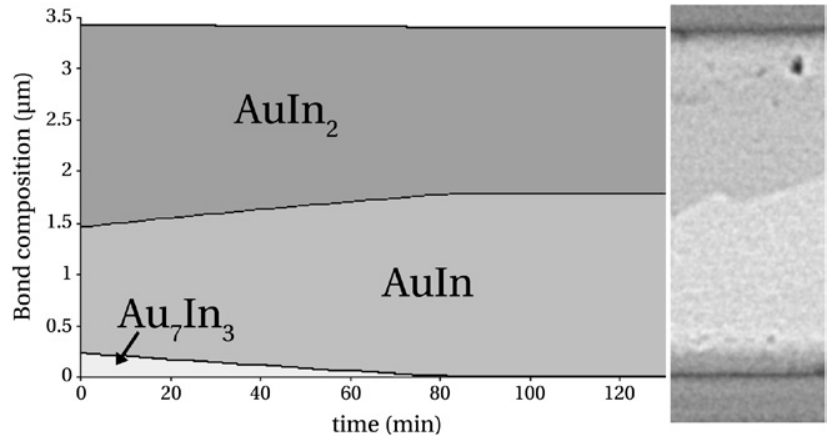

Figure 9. Left: modelling of further annealing at $150{ }^{\circ} \mathrm{C}$; to be compared with the bond shown in figure 6 (starting configuration resulting from the simulation of the bonding process applied to the bond shown in figure 6). Right: selected area of the same bond.

and thus the liquid composition is uniform (and equal to the interfacial composition with $\mathrm{AuIn}_{2}$ ); (iii) the diffusion of In into solid $\mathrm{Au}$ is calculated using an explicit Finite Difference Method, with a Landau transformation to follow the variable thickness of this domain (50 mesh points were set up in $\mathrm{Au}$ ); (iv) the various densities of the different phases are accounted for (i.e. the overall domain size can change).

The simulation result of a bonding process corresponding to the bond presented in figure 4 is shown in figure 8. During heating, the growth of the $\mathrm{AuIn}_{2}$ layer has already started while the thicknesses of the two other IMCs remain almost unchanged. When approaching the bonding temperature $\left(200{ }^{\circ} \mathrm{C}\right)$, which is reached after $9 \mathrm{~min}$, all three IMCs start to grow faster but the AuIn phase still remains as a thin layer. The velocity of the AuIn/AuIn 2 and $\mathrm{AuIn} / \mathrm{Au}_{7} \mathrm{In}_{3}$ interfaces changes direction once the liquid indium disappears after about 11 min (first angular point in the curves). A second noticeable event is when the solid gold is fully consumed (after $14 \mathrm{~min}$ ): the velocity of the $A u I n / A u_{7} I_{3}$ interface changes direction again, thus allowing the AuIn to expand at the expense of the two other neighbouring IMCs. These velocity changes of the interfaces are due to the In flux through either $\mathrm{AuIn}_{2}$ (for the first change) or $\mathrm{Au}_{7} \mathrm{In}_{3}$ (for the second inversion), which becomes zero to ensure the solute conservation when the corresponding In source (for the first event) and sink (for the second) disappear. The bond structure does not evolve much after completion of the bonding plateau $(24 \mathrm{~min})$. At the end of the bonding process, the microstructure is made of $0.4 \mu \mathrm{m}$ $\mathrm{AuIn}_{2}, 1.4 \mu \mathrm{m}$ of AuIn and $0.4 \mu \mathrm{m}$ of $\mathrm{Au}_{7} \mathrm{In}_{3}$. There is a slight difference compared to the experimental observations, where the reaction was slightly more advanced. Note that the overall thickness of the bond changes over the bonding period due to the density differences between the various phases (decrease of $0.17 \mu \mathrm{m})$.

An additional $150{ }^{\circ} \mathrm{C}$ heat treatment was also simulated. For that purpose, the bonding process applied to the bond shown in figure 6 was first simulated. The resulting IMCs' thicknesses were then used as a starting point for the simulation of a $150{ }^{\circ} \mathrm{C}$ annealing. The result (figure 9) shows that $\mathrm{Au}_{7} \mathrm{In}_{3}$ is progressively consumed and disappears completely after $80 \mathrm{~min}$, leaving only AuIn and AuIn 2 , as observed in the experiments. 


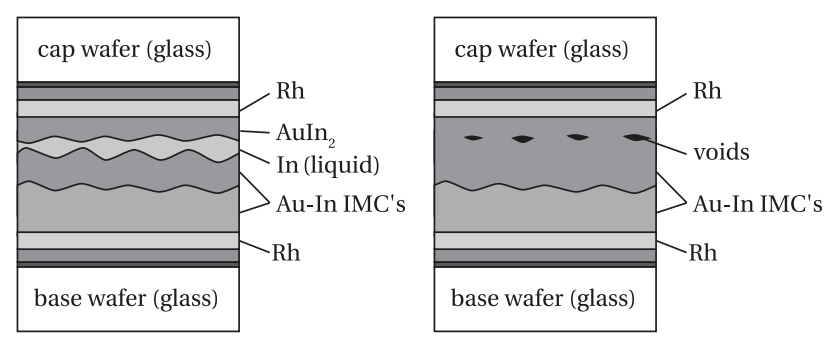

Figure 10. A possible explanation for the formation of voids: when the $\mathrm{Au}-\mathrm{In}$ IMCs formed by reaction with $\mathrm{Au}$ on the base wafer come into contact with the $\mathrm{AuIn}_{2}$ formed on the cap wafer side by reaction with the Au seed layer, the irregularities of the two solidliquid interfaces lead to the formation of voids.

\section{Discussion}

First, some comparisons can be made between our experimental results, those of the literature mentioned in section 1 and our simulations. Concerning the microstructure, we confirm the presence of the $\mathrm{AuIn}_{2}$ phase in the bonds, as previously observed. However, the AuIn phase was observed with thicker layers than reported in the previous studies on $\mathrm{Au}-\mathrm{In}$ bonding, as well as in our diffusion couples experiments [11, 12]. Nevertheless, when $\mathrm{Au}$ and In have a finite size compared to the intermetallic layers, the model shows that the situation is significantly different from that of diffusion couples. As long as In and Au remain, the AuIn layer is thin, but as soon as they disappear, this phase thickens rapidly at the expense of the two other IMCs. This behaviour is similar to the case of the $\mathrm{Cu}_{3} \mathrm{Sn}$ compound which is observed during $\mathrm{Cu}-\mathrm{Sn}$ SLID bonding [15]. $\mathrm{Au}_{7} \mathrm{In}_{3}$ was also observed, although the nominal composition lies above 50 at.\% In, but it disappears when the bond is subsequently annealed to reach thermodynamic equilibrium. The optimal bonding time and temperature were found to be close to the parameters used by Waelti [7]. The pressure applied during bonding, on the contrary, is smaller in our case (2.3 versus $8 \mathrm{MPa}$ ) and, consequently, the hermeticity yield will certainly improve if the pressure is increased.

SEM observations showed that submicron voids are present near the $\mathrm{AuIn}_{2} / \mathrm{AuIn}$ interface (figure 4), which could have various origins. The majority of the IMCs' growth takes place between the In from the cap wafer and the Au from the base wafer. However, some $\mathrm{AuIn}_{2}$ is formed on the cap wafer side, by the reaction of In with the Au seed layer underneath (the $0.1 \mu \mathrm{m}$ thick layer). The voids found in the bonds are thus more likely formed when the two irregular solid-liquid interfaces come into contact, because there is not enough liquid remaining to fill the spaces left by the further lateral growth (or coarsening) of the $\mathrm{AuIn}_{2}$ grains (see figure 10), and because there is a shrinkage due to the formation of an IMC denser than the liquid In. By applying solute conservation, we find that a $0.4 \mu \mathrm{m}$-thick layer of $\mathrm{AuIn}_{2}$ can be formed on the cap wafer side. In the SEM micrographs, the voids are found at an approximate distance of $0.6 \mu \mathrm{m}$ from the Rh layer of the cap wafer. Therefore, this observation supports the assumption that the $\mathrm{AuIn}_{2}$ irregularities of the two encountering solid-liquid interfaces lead to the formation of voids. However, the voids could also arise from the roughness and thickness inhomogeneities of the initial electroplated layers. Indeed, the inhomogeneities may not be compensated by a relatively thin bond, which, moreover, shrinks due to density differences. In Au-In diffusion couples, voids located within the $A_{4} I_{n}$ phase close to the interface with $\mathrm{Au}$ were explained on the basis of the Kirkendall effect. But the voids are unlikely formed by this effect in the present situation, as they are located within the $\mathrm{AuIn}_{2}$ phase.

It remains unclear whether the leakage is caused by the observed porosity (if it is interconnected) or if there is another reason that was not detected (e.g. poor interfacial adhesion between the IMCs and Rh). Unfortunately, the source of the leaks could not be pinpointed by SEM observations. Samples were also observed using x-ray tomography, but the spatial resolution of this technique $(0.37 \mu \mathrm{m})$ was not good enough to be conclusive. Addressing this specific issue would require an experimental method which has both a very good spatial resolution and the capacity of imaging a whole bonding frame.

It seems that there is a correlation between the hermeticity of a package and its location on the wafer: most of the hermetic packages were located in regions of the wafer where the In electroplated layer was slightly thicker. However, this thickness cannot be increased too much in order to avoid having unreacted indium in the bond, which would partially remelt in subsequent operations.

The attempts to improve the hermeticity yield, with a nominal composition of about 50 at.\% In, gave only poor results. One possible reason to explain this failure may be the larger thicknesses of the electroplated layers used in this case. The thickness uniformity was consequently not so good and quite large differences (up to $0.6 \mu \mathrm{m}$ ) in the total thicknesses between different locations on the wafers were noticed. Even if a large pressure is applied during bonding, it is not sure that this can compensate these differences (and the lack of planarity of the wafers themselves).

Critical parameters to achieve hermeticity include the uniformity and roughness of the electroplated layers, as well as the planarity of the wafers. In order to improve the hermeticity yield, a change in the geometry of the bonding frame may be considered: a wider bond would decrease the probability to find porosity extending through the entire bond. Alternatively, the bond frame might be decomposed into several concentric frames of narrower width. This would reduce the current crowding effect and thus help improve the uniformity of the electroplated layers. Also the Au and In layers may be differently distributed between the cap and base wafers.

\section{Conclusion}

Homogeneous $\mathrm{Au}-\mathrm{In}$ bonds were achieved with a nominal composition of about 60 at.\% In. The optimal bonding parameters were found to be $15 \mathrm{~min}$ at $200{ }^{\circ} \mathrm{C}$ with an applied pressure of about 1.8 bar. The three IMCs AuIn 2 , AuIn and $\mathrm{Au}_{7} \mathrm{In}_{3}$ were present in the microstructure after bonding. Hermeticity tests showed that $17 \%$ of the packages were 
hermetically sealed. Although the leaks origin could not be identified and the attempts to improve the hermeticity yield remained unsuccessful, the feasibility of $\mathrm{Au}-\mathrm{In}$ hermetic bonds was demonstrated. In addition, some bonds successfully withstood heating at $350{ }^{\circ} \mathrm{C}$, which is much more severe than what they are susceptible to really undergoing during the subsequent mounting operations of MEMS fabrication. Finally, the 1D numerical model, developed on the basis of diffusion couple experiments $[11,12]$ could be applied successfully to $\mathrm{Au}-\mathrm{In}$ bonds, i.e. when a finite thickness and non-isothermal situation are considered. It reproduces well the experimental observations, thus allowing bonding optimisation (composition, thermal cycle, time) for $\mathrm{Au}-\mathrm{In}$, but also demonstrating the interest of using numerical simulations calibrated on preliminary careful diffusion couple experiments for bonding operations in general.

\section{References}

[1] Bernstein L 1966 J. Electrochem. Soc. 113 1282-8

[2] Bernstein L and Bartholomew H 1966 Trans. Metall. Soc. AIME 236 405-12
[3] Okamoto H and Massalski T 1986 Binary Alloy Phase Diagrams vol 1 (Metals Park, Ohio: American Society for Metals)

[4] Lee C, Wang C and Matijasevic G 1993 J. Electron. Packag. $115201-7$

[5] Shi J, Xie X, Stubhan F and Freytag J 2000 J. Electron. Packag. 122 168-71

[6] Sohn Y, Wang Q, Ham S, Jeong B, Jung K, Choi M, Kim W and Moon C 2007 IEEE Electron. Compon. Technol. Conf. 1 633-7

[7] Waelti M 2000 Packaging of CMOS IR Microsystems, $P h D$ Thesis ETHZ, Zurich

[8] Wang T, Shen Z, Ye R, Xie X, Stubhan F and Freytag J 2000 J. Electron. Mater. 29 443-7

[9] Xie X, Wang T, Shi J, Ye R, Stubhan F and Freytag J 2000 Solder. Surf. Mount. Technol. 12 40-4

[10] Zhang W and Ruythooren W 2008 J. Electron. Mater. 37 1095-11

[11] Deillon L, Hessler T, Hessler-Wyser A and Rappaz M 2014 Acta Mater. 79 258-67

[12] Deillon L 2012 Soudure par interdiffusion dans les systèmes $\mathrm{Au}-\mathrm{In}$ et In-Ni: application à des composants microélectroniques, PhD Thesis EPFL, Lausanne

[13] Gueissaz F, Maggini R, Piguet D, Sallin M and Struchen D 2005 Des., Test., Integr. Packag. MEMS/MOEMS pp 394-9

[14] Gueissaz F and Randin J P 2009 US Patent 7601537 B2

[15] Li J, Agyakwa P and Johnson C 2011 Acta Mater. 59 1198-211 